\title{
Suppression of PAMPs, Pathogen-Associated Microbial Patterns, Induced Cytokine Synthesis of PBMC, Human Blood Mononuclear Cells, by Immunoglobulin Preparation
}

\author{
Ayumi Yamamoto ${ }^{1}$, Noriko N. Miura ${ }^{1}$, Toshiaki Oharaseki ${ }^{2}$, Kei Takahashi ${ }^{2}$, Shiro Naoe ${ }^{2}$, Kazuo \\ Suzuki $^{3}$ and Naohito Ohno ${ }^{1, *}$ \\ ${ }^{1}$ Laboratory for Immunopharmacology of Microbial Products, School of Pharmacy, Tokyo University of Pharmacy and \\ Life Sciences, 1432-1 Horinouchi, Hachioji, Tokyo 192-0392, Japan \\ ${ }^{2}$ Department of Pathology, Toho University Ohashi Medhcal Center, 2-17-6 Ohashi, Meguro, Tokyo 153-8515, Japan \\ ${ }^{3}$ Inflammation Program, Department of Immunology, Chiba University Graduate School of Medicine, 1-8-1 Ihana, \\ Chuo-ku, Chiba, Chiba 260-8670, Japan
}

\begin{abstract}
The applications of immunoglobulin preparation for intravenous injection (IVIg) for various intractable diseases are increasing. The two major clinical indications for IVIg are the replacement therapy and the anti-inflammation therapy for a variety of acute and chronic autoimmune diseases. One of the proposed mechanisms of IVIg activity is the modulation of cytokine expression and function; therefore, we analyzed the effect of IVIg on pathogen-associated molecular pattern (PAMP)-induced cytokine production by peripheral blood mononuclear cells (PBMCs). The production of tumor necrosis factor- $\alpha$ (TNF- $\alpha$ ) as a result of stimulation with lipopolysaccharide (LPS), polyinosinic-polycytidylic acid sodium salt (Poly I:C), or Pam3CysSerLys4 (Pam3) was significantly inhibited by sulfonated-IVIg (S-IVIg), or by F(ab') 2 . Assessed by one-color microarray analysis, the expressions of 229 genes were inhibited to $1 / 200$ or less by $F\left(a b^{\prime}\right)_{2}$. On the other hand, the expressions of 159 genes were increased by more than 100-fold by $\mathrm{F}\left(\mathrm{ab}^{\prime}\right)_{2}$. According to these results, it was suggested that IVIg inhibits inflammatory PAMPs-induced cytokine production by PBMCs, due to the modulation of varieties of gene expression.
\end{abstract}

Keywords: anti-inflammatory effect, intravenous immunoglobulin (IVIg) therapy, microarray analysis, pathogen-associated microbial patterns (PAMPs), peripheral blood mononuclear cell (PBMC).

\section{INTRODUCTION}

Since the development of a method for purifying and concentrating immunoglobulin $\mathrm{G}$ ( $\operatorname{IgG}$ ) in plasma using Cohn cold ethanol fractionation in 1941, IgG extracted from human blood has been used as a pharmaceutical product for the purpose of preventing and treating bacterial and viral infections. This product is referred to as an immunoglobulin preparation.

While it is used for the prevention and treatment of infections as well as for IgG replacement therapy, it has come to be used for the treatment of numerous autoimmune diseases following a report by Imbach et al. [1] in 1981 that intravenous immunoglobulin (IVIg) restores the platelet count in idiopathic thrombocytopenic purpura (ITP) patients. In Japan, autoimmune diseases covered by the national health insurance include ITP, Kawasaki disease, chronic inflammatory demyelinating polyneuropathy, Guillain-Barré syndrome, and pemphigus. IVIg threpy is recommended to these

*Address correspondence to this author at the Laboratory for Immunopharmacology of Microbial Products, School of Pharmacy, Tokyo University of Pharmacy and Life Sciences, 1432-1 Horinouchi, Hachioji, Tokyo 1920392, Japan; Tel./Fax: +81-42-676-5561; E-mail: ohnonao@toyaku.ac.jp autoimmune diseases. IVIg has also been apploed to treat systemic lupus erythematosus (SLE) [2, 3], Alzheimer's disease [4], and habitual miscarriage [5], as well as during organ transplant [6], and has demonstrated its effectiveness in those cases.

Although IVIg is applied to treat a number of diseases, its mechanism of action has yet to be clearly determined [7-10]. There are various kind of autoimmune diseases, and at least in part are induced by inballance of the immune surveillance system $[8,9]$. Immune system includes various subsystems, such as innate vs. acquired, systemic vs. mucosal, primary vs. secondary, and so on. It has been clearly demonstrated that activation of the innate immunity by various PAMPs during microbial infection strongly influenced the following acquired immunity. As the onset of autoimmune diseases is considered to be closely related to the microbial infection either directly or indirectly, analysis of the action of PBMCs stimulated by PAMPs is important to clarify the mechanism of IVIg.

LPS is a structural component of the cell wall of Gram negative bacteria such as Escherichia coli, and Toll-like receptor (TLR) 4, myeloid differentiation factor 2 (MD-2), and cluster of differentiation (CD) 14 form a complex to induce inflammation from two directions, consisting of a myeloid differentiation factor 88 (MyD88) -dependent pathway [11] 
and a pathway mediated by the Toll/interleukin-1 receptor (TIR) domain containing adaptor inducing interferon $\beta$ (TRIF) [12]. Pam3 is a synthetic lipopeptide that is recognized through the cooperation of TLR1 with TLR2, leading to the activation of nuclear factor-kappa B (NF- $\mathrm{B})$ [13]. Polyinosinic-polycytidylic acid sodium salt (Poly I:C) is a synthetic double-stranded RNA (dsRNA) that induces an immune response to viral infection. $N F-\kappa B$ is activated in two ways: a pathway mediated by dsRNA-activated protein kinase (PKR) [14] and a pathway associated with TLR3 [15].

As shown above the microbial infection and the autoimmune diseases are directly and/or indirectly link in each other. In the present study, the effect of IVIg on PAMPsinduced cytokine production by PBMCs were examined and proposed mechanisms for the anti-inflammatory action.

\section{MATERIALS AND METHODS}

\section{Immunoglobulin Preparations}

Immunoglobulin preparations used in this study were SIVIg (Kenketsu Venilon-I; Chemo-Sero-Therapeutic Research Institute) and Fc-depleted immunoglobulin preparation $\left(\mathrm{F}(\mathrm{ab})_{2}\right.$, Kenketsu Jyochu Globulin "Kaketsuken;" Chemo-Sero-Therapeutic Research Institute). S-IVIg contained glycin, albumin, and D-mannitol as stabilizer. F $\left(a b^{\prime}\right)_{2}$ contained glycin and sodium chloride as stabilizer. Those preparations were dissolved in the solvent specified in the instruction and frozen at $-30^{\circ} \mathrm{C}$ until use.

\section{Media and Buffers}

RPMI 1640 medium (Prime) was used, to which gentamycin sulfate (Wako Pure Chemical Industries) was added at a concentration of $50 \mu \mathrm{g} / \mathrm{ml}$. Fetal bovine serum (FBS) (Equitec) was used after inactivation at $56^{\circ} \mathrm{C}$ for 30 minutes. Physiological saline (Otsuka Normal Saline) and injection solvent (Otsuka Distilled Water) were purchased from Otsuka Pharmaceutical Co., Ltd. 3,3',5,5'-tetramethylbenzidine (TMB) Microwell Peroxidase Substrate was purchased from Funakoshi Co. Japan.

\section{Plates}

A 96-well Multiwell Plate 96FII (Sumilon) was used for cell culture. A Nunc plate (F96 MaxiSorp Nunc-Immuno Plate Nunc; Nunc) and an enzyme-linked immunosorbent assay (ELISA) plate (half-area, half-plate: 96-well flatbottomed and high binding; Greiner Bio One) were used for ELISA.

\section{Blood Collection}

Blood samples were collected using Venoject II vacuum blood collection tubes (heparinized blood collection tubes) with a Sureshield Safety Winged Needle Set (Terumo). Blood sampling was performed after approval from the university physicians based on the provisions established by the ethics committee of our university.

\section{PAMPs}

E. coli serotype 0111:B4 of LPS (lipopolysaccharide) was purchased from Sigma-Aldrich and dissolved in physiological saline to a concentration of $1 \mathrm{mg} / \mathrm{ml}$. Pam3 was purchased from EMC Microcollection GmbH (Tubingen, Ger- many) and dissolved in physiological saline to a concentration of $1 \mathrm{mg} / \mathrm{ml}$. Poly I:C was purchased from SigmaAldrich and dissolved in PBS to a concentration of 10 $\mathrm{mg} / \mathrm{ml}$. Candida albicans water-soluble extracellular polysaccharide (CAWS) prepared by our laboratory was dissolved in phosphate-buffered saline (PBS) to a concentration of $1 \mathrm{mg} / \mathrm{ml}$ [16]. Oxidized C. albicans (OX-CA) prepared by our laboratory was dissolved in physiological saline to a concentration of $5 \mathrm{mg} / \mathrm{ml}$ [17].

\section{Antibodies}

For IL- 8 and TNF- $\alpha$ ELISA, mouse anti-human IL- 8 or TNF- $\alpha$ (BD Bioscience) was used for the primary antibody and biotinylated mouse anti-human IL- 8 or TNF- $\alpha$ monoclonal Ab (BD Bioscience) was for the secondary antibody. The reaction was detected by avidin-peroxidase and horseradish peroxidase (HRP)-streptavidin conjugate (Zymed Laboratories, Inc.).

\section{PBMC Isolation}

Blood samples from healthy donors $(n=3)$ were collected into heparinized vacuum tubes. The samples were centrifuged for 10 minutes at $2800 \mathrm{~g}$, and the buffy coat layer containing white blood cells was recovered and diluted with an equal volume of physiological saline. The supernatant (plasma) was heated at $56^{\circ} \mathrm{C}$ for 30 minutes to deactivate the complement. Three-milliliter aliquots of Histopaque-1077 were added to $15 \mathrm{ml}$ centrifuge tubes (Iwaki Glass) and the buffy coat was layered. This was followed by centrifugation for 30 minutes at $3000 \mathrm{~g}$. The supernatant was discarded and the resulting white blood cell layers were diluted with water for injection to lyse red blood cells. The resulting mixture was washed three times with RPMI 1640 to prepare PBMC fraction for use.

\section{Cell Culture}

The isolated PBMCs were diluted to $1 \times 10^{6}$ cells $/ \mathrm{ml}$ (with 10\% inactivated autoplasma RPMI 1640), and the preliminary study was conducted to determine the optimum culture condition to analyze the effect of IVIg on PAMPinduced cytokine production by PBMCs.. PBMCs were cultured up to 48 hours following the addition of PAMPs (LPS, Pam3, Poly I:C, CAWS, and OX-CA), followed by the recovery of the culture supernatant and measurement of the concentration of TNF- $\alpha$ by ELISA. The concentrations of PAMPs that moderately induced TNF- $\alpha$ production were 1 $\mathrm{ng} / \mathrm{ml}$ for LPS, $100 \mathrm{ng} / \mathrm{ml}$ for Pam3, $10 \mu \mathrm{g} / \mathrm{ml}$ for Poly I:C, 1 $\mu \mathrm{g} / \mathrm{ml}$ for CAWS, and $1 \mu \mathrm{g} / \mathrm{ml}$ for OX-CA. Optimum culture period was around 8 hours.

\section{Microarray}

RNA extraction and one-color microarray analysis were performed by Hokkaido System Science Co., Ltd. (HSS). After culturing PBMCs for 30 minutes with $\mathrm{F}\left(\mathrm{ab}^{\prime}\right)_{2}$, the cells were stimulated with Poly I:C $(10 \mu \mathrm{g} / \mathrm{ml})$ for 3 hours. The samples were then stored in the pretreatment solvent for stabilize RNA and sent to HSS for microarray analysis. The samples consisted of a "control" to which only Poly I:C was added and " $\left.\mathrm{F}(\mathrm{ab})_{2}\right)^{\text {" }}$ to which both $\mathrm{F}(\mathrm{ab})_{2}$ and Poly I:C were added. Microarray analysis was carried out as follows: cDNA synthesis, labeling (cyanine 3), amplification of 

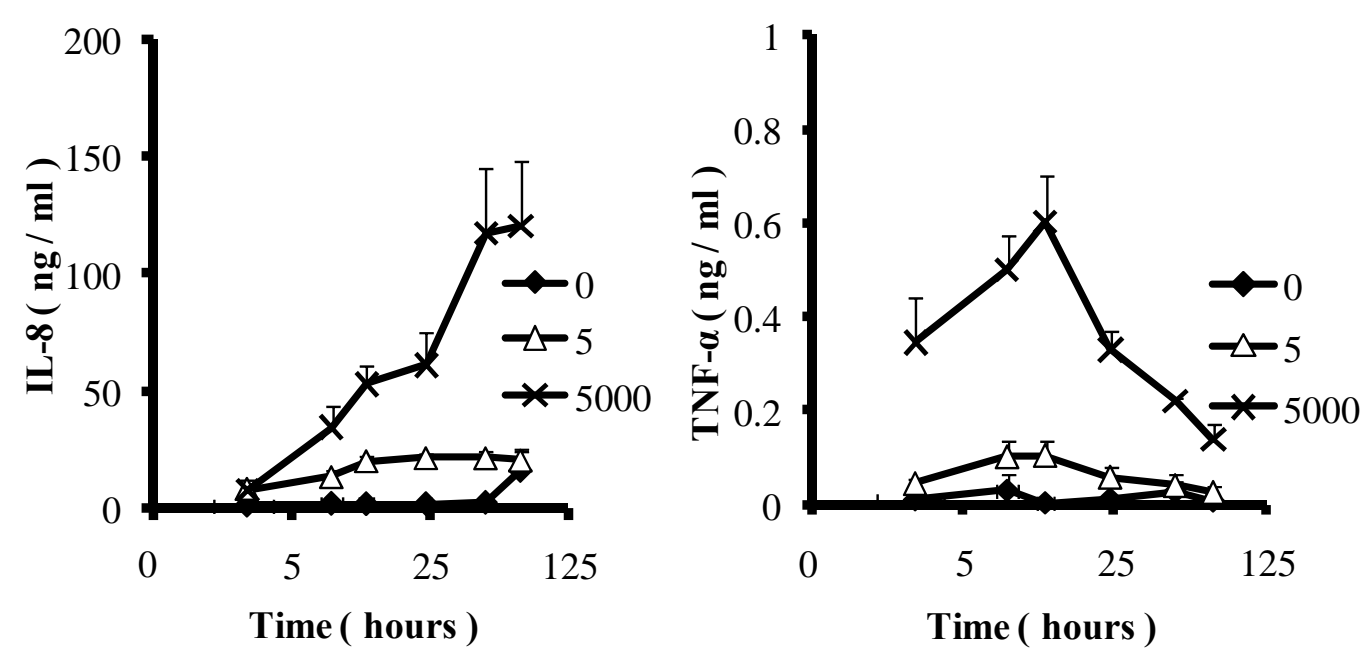

Fig. (1). Kinetics of IL-8 and TNF- $\alpha$ from PBMC stimulated with solid phase IVIg. PBMC was cultured for $3 \mathrm{~h}-72 \mathrm{~h}$ with solid phase IVIg. Zero (closed squares), 5 (open triangles), and 5000 (crosses) $\mu \mathrm{g} / \mathrm{ml}$ of P-IVIg were added to the plate. X-axis was culture time. Y-axis was concentration of IL- 8 or TNF- $\alpha(\mathrm{ng} / \mathrm{ml})$. Concentrations of IL- 8 and TNF- $\alpha$ were measured by ELISA. Values represented means + SEM. Experiments were done in tripricate, and a representative data from one donor was shown.
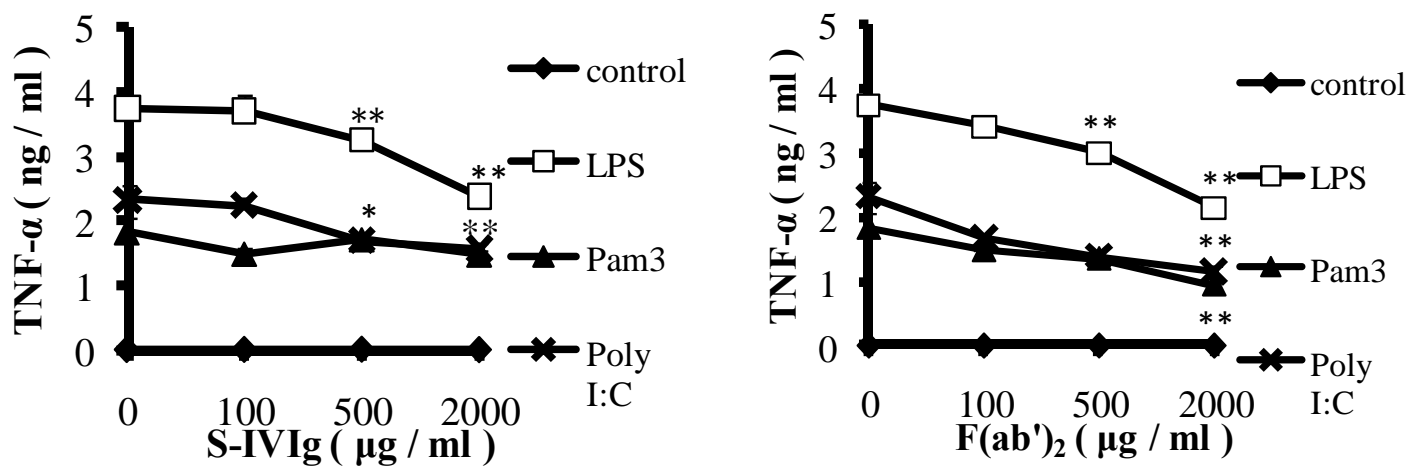

Fig. (2). PAMP-induced TNF- $\alpha$ production by PBMCs cultured with IVIg or F(ab') $)_{2}$. PBMCs were cultured for 8 h with S-IVIg or F(ab') 2 and a variety of PAMPs: LPS $1 \mathrm{ng} / \mathrm{ml}$ (open squares); Pam3 $100 \mathrm{ng} / \mathrm{ml}$ (closed triangles); and Poly I:C $10 \mu \mathrm{g} / \mathrm{ml}$ (crosses). The control (closed squares) is saline. X-axis is the concentration of S-IVIg or $\mathrm{F}(\mathrm{ab})_{2}$. Y-axis is the concentration of TNF- $\alpha$ measured by ELISA. Values are shown as the means +SEM. p values were determined by Student's t test. ${ }^{*} \mathrm{p}<0.05 * * \mathrm{p}<0.01$. Experiments were done in tripricate, and a representative data from one donor was shown.

cRNA (Quick Amp Labeling Kit; Agilent Technologies), purification of labeled cRNA (RNeasy mini spin columns; Qiagen), preparation of cRNA target solution, washing and drying the array, scanning (Agilent gene expression scanner), and data generation (excluding data in which expression levels were extremely low and data in which measurement errors were excessively high after normalization, etc.).

\section{Statistical Analyses}

Student's t-test was used to test for the presence of significant differences.

\section{RESULTS}

\section{Effect of IVIg on PAMP-Induced Cytokine Production}

Preliminary study was conducted to determine the optimum culture condition to analyze the effect of IVIg on PAMP-induced cytokine production by PBMCs. PBMCs were cultured up to 48 hours in the presence or absence of PAMPs (LPS, Pam3, Poly I:C, CAWS, and OX-CA) and measured the concentration of $\mathrm{TNF}-\alpha$ in the culture super- natant by ELISA. The concentrations of PAMPs that moderately induced TNF- $\alpha$ production were $1 \mathrm{ng} / \mathrm{ml}$ for LPS, 100 $\mathrm{ng} / \mathrm{ml}$ for Pam3, $10 \mu \mathrm{g} / \mathrm{ml}$ for Poly I:C, $1 \mu \mathrm{g} / \mathrm{ml}$ for CAWS, and $1 \mu \mathrm{g} / \mathrm{ml}$ for OX-CA. Optimum culture period was around 8 hours. To demonstrate the optimum culture condition more precisely, TNF- $\alpha$ and IL- 8 production of PBMCs stimulated with IVIg coated on the culture plate were measured up to 48 h (Fig. 1). As shown in Fig. (1), peak cytokine concentration for TNF- $\alpha$ was around $8 \mathrm{~h}$. In contrast, IL- 8 concentartion was gradually increased during the cultivation period. From these findings, we chose $8 \mathrm{~h}$ culture for the following experiments.

Then, the effect of IVIg on PAMP-induced cytokine production was examined. PBMCs were incubated for $30 \mathrm{~min}$ utes in the presence or absence of IVIg (S-IVIg, F $\left.\left(\mathrm{ab}^{\prime}\right)_{2}\right)$ and then stimulated with various PAMPs (LPS, Pam3, Poly I:C) for $8 \mathrm{~h}$ at $37^{\circ} \mathrm{C}$ and $5 \% \mathrm{CO}_{2}$. TNF- $\alpha$ concentration of the resulting supernatant was measured by ELISA (Fig. 2). The production of TNF- $\alpha$ as a result of stimulation with LPS and Pam3 was significantly inhibited by S-IVIg, and TNF- $\alpha$ pro- 

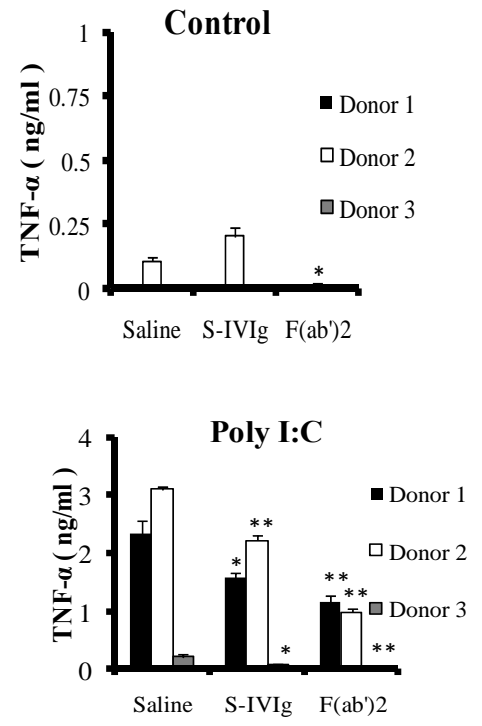
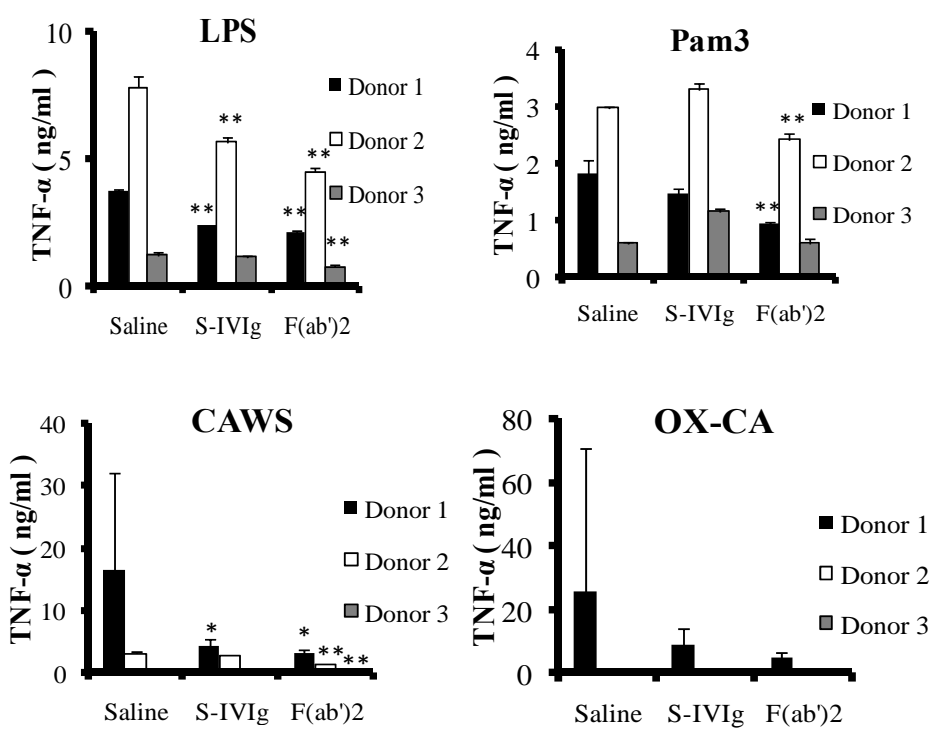

Fig. (3). Production of TNF- $\alpha$ from 3 donors PBMC cultured with IVIg and variety of PAMPs. Three donors PBMC were cultured for $8 \mathrm{~h}$ with S-IVIg or F(ab') $)_{2}$ and variety of PAMPs, LPS 1ng/ml, or Pam3 100ng/ml, Poly I:C $10 \mu \mathrm{g} / \mathrm{ml}$, CAWS $1 \mu \mathrm{g} / \mathrm{ml}$, and OX-CA 1 $\mu \mathrm{g} / \mathrm{ml}$. Concentration of TNF- $\alpha$ was measured by ELISA. Values represented means +SEM. p values shown were determined by the Student's $t$ test. $* \mathrm{p}<0.05 * * \mathrm{p}<0.01$.
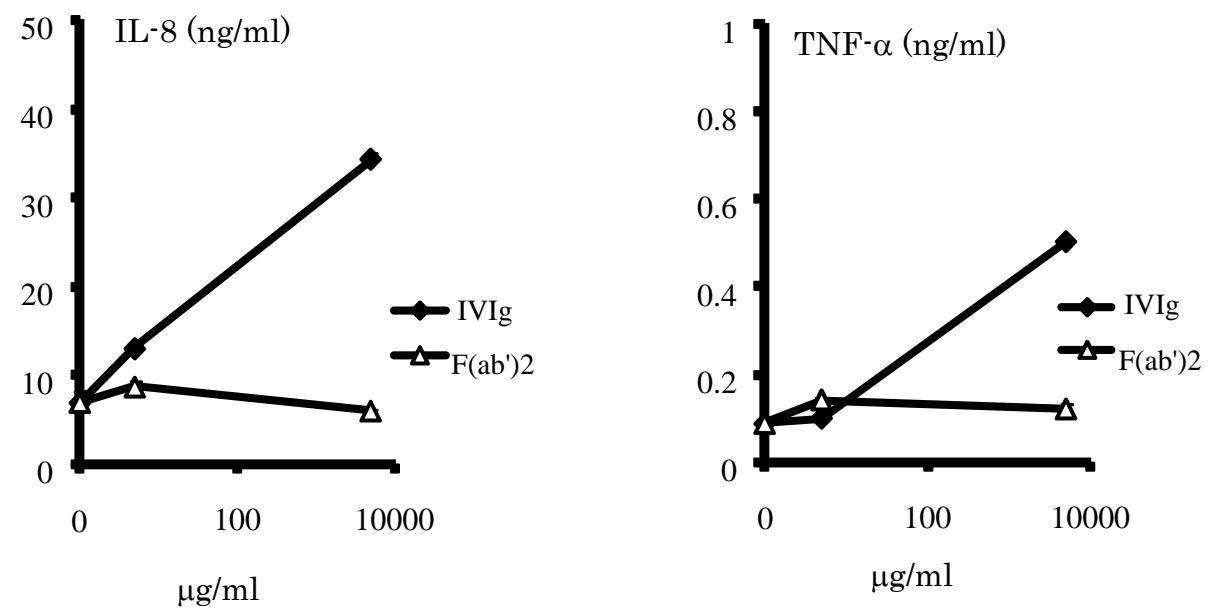

Fig. (4). Production of IL- 8 and TNF- $\alpha$ from PBMC cultured with solid phase IVIg or F(ab') ${ }_{2}$. PBMC was cultured for $8 \mathrm{~h}$ with solid phase IVIg or $\mathrm{F}(\mathrm{ab})_{2}$. X-axis was concentration of solid phase IVIg (closed squares) or $\mathrm{F}(\mathrm{ab})_{2}$ (open triangles). Y-axis was concentration of IL-8 or TNF- $\alpha$. Concentrations of IL- 8 and TNF- $\alpha$ were measured by ELISA. Values represented means +SEM. Experiments were done in tripricate, and a representative data from one donor was shown.

duction resulting from the stimulation with all PAMPs was significantly inhibited by $\mathrm{F}(\mathrm{ab})_{2}$. Next, we examined the effect of IVIg (S-IVIg and $\left.F\left(a^{\prime}\right)_{2}\right)$ on cytokine production induced by $C$. albicans-derived PAMPs (CAWS, OX-CA). Similar to other PAMPs, S-IVIg and $\mathrm{F}\left(\mathrm{ab}^{\prime}\right)_{2}$ inhibited its TNF- $\alpha$ production (data not shown). In addition, to test the individual differences of inhibitory action, we analyzed data from three individuals (Fig. 3). As shown in Fig. (3), all three donors respond to various PAMPs and produced significant concentration of TNF- $\alpha$. Amount of TNF- $\alpha$ was different in each individual, however, the production of TNF- $\alpha$ was inhibited significantly in all donors by both IVIg and $\mathrm{F}(\mathrm{ab}$ ')2. From these findings, IVIg was found to inhibit TNF- $\alpha$ production of PBMC stimulated with various PAMPs.
Immunoglobulin is consisted of two functional regions, antigen binding region and constant region ( $\mathrm{Fc}$ fragment) which is an adaptor for leukocyte-signaling. Function of IVIg might be mediated through both of the regions. It is well known that cross-linking of Fc receptors and/or complement receptors by immune complex significantly enhance the phagocytic response as well as the inflammatory reactions. When IVIg was coated onto the culture plate to mimic cross-linking and cultured with PBMC, strong cytokine production was induced without any other stimulus (Fig. 1). In contrast, coating $\mathrm{F}\left(\mathrm{ab}^{\prime}\right)_{2}$ did not induce such inflammatory reactions from PBMC (Fig. 4). These facts suggested that function of IVIg is mediated through both Fc-receptor and antigen-binding sites, and $\mathrm{F}(\mathrm{ab})_{2}$ is through only the antigen-binding sites. As shown above, both S-IVIg and $\mathrm{F}\left(\mathrm{ab}^{\prime}\right)_{2}$ 
Table 1. Genes of polyIC-Stimulated PBMC Downregulated by F(ab')2 Treatment*

\begin{tabular}{|c|c|c|c|}
\hline Control & $\mathbf{F}\left(\mathbf{a} \mathbf{b}^{\prime}\right) 2$ & Log2 Ratio & Description \\
\hline 208.2 & 0.003 & -16.16 & chemokine (C-C motif) receptor 7 (CCR7) \\
\hline 363.1 & 0.005 & -16.1 & interleukin 1, beta (IL1B) \\
\hline 255.6 & 0.005 & -15.6 & interleukin 1 receptor antagonist (L1RN) \\
\hline 157.6 & 0.003 & -15.46 & chemokine (C-X-C motif) receptor 4 (CXCR4) \\
\hline 82.88 & 0.002 & -15.02 & chemokine (C-C motif) receptor-like 2 (CCRL2) \\
\hline 486.6 & 0.024 & -14.33 & chemokine (C-C motif) ligand 4 (CCL4) \\
\hline 318 & 0.017 & -14.18 & tumor necrosis factor (TNF) \\
\hline 136.7 & 0.008 & -14.09 & S100 calcium binding protein A8 (S100A8) \\
\hline 45.58 & 0.003 & -13.96 & MOX44, TSPAN25 (CD53) \\
\hline 67.1 & 0.006 & -13.57 & toll-like receptor 2 (TLR2) \\
\hline 97.73 & 0.008 & -13.54 & chemokine (C-X-C motif) ligand 3 (CXCL3) \\
\hline 148.1 & 0.013 & -13.51 & oncostatin M (OSM) \\
\hline 46.83 & 0.004 & -13.51 & allograft inflammatory factor 1 (AIF1) \\
\hline 62.79 & 0.006 & -13.39 & hepatitis A virus cellular receptor 2 (HAVCR2) \\
\hline 105.9 & 0.011 & -13.29 & chemokine (C-C motif) ligand 23 (CCL23) \\
\hline 516.9 & 0.057 & -13.15 & chemokine (C-C motif) ligand 3-like 3 (CCL3L3) \\
\hline 157.4 & 0.019 & -13.01 & interleukin 3 receptor, alpha (IL3RA) \\
\hline 59.27 & 0.009 & -12.69 & endothelin 1 (EDN1) \\
\hline 79.45 & 0.013 & -12.62 & ras-related C3 botulinum toxin substrate 2 (rho family, small GTP binding protein Rac2 (RAC2) \\
\hline 70.87 & 0.015 & -12.16 & interleukin 4 receptor (IL4R) \\
\hline 371.4 & 0.091 & -12 & Inhibin, beta A (INHBA) \\
\hline 519.9 & 0.138 & -11.88 & mRNA for pLD78 peptide (CCL3) \\
\hline 191.4 & 0.052 & -11.83 & ficolin (collagen/fibrinogen domain containing) 1 (FCN1) \\
\hline 50.4 & 0.016 & -11.6 & 0 serpin peptidase inhibitor, clade B (ovalbumin), member 2 (SERPINB2) \\
\hline 131.3 & 0.046 & -11.49 & interleukin 6 (interferon, beta 2) (IL6) \\
\hline 137.8 & 0.056 & -11.27 & plasminogen activator, urokinase receptor (PLAUR) \\
\hline 72.98 & 0.04 & -10.85 & lymphotoxin beta (TNF superfamily, member 3) (LTB) \\
\hline 111.6 & 0.064 & -10.77 & TYRO protein tyrosine kinase binding protein (TYROBP) \\
\hline 64.06 & 0.042 & -10.59 & NLR family, pyrin domain containing 3 (NLRP3) \\
\hline 46.52 & 0.035 & -10.38 & lysozyme (renal amyloidosis) (LYZ) \\
\hline 46.07 & 0.036 & -10.34 & chemokine (C-C motif) receptor 1 (CCR 1$)$ \\
\hline 48.66 & 0.042 & -10.19 & glia maturation factor, gamma (GMFG) \\
\hline 243.5 & 0.214 & -10.15 & serglycin (SRGN) \\
\hline 55.59 & 0.055 & -9.98 & granzyme B (granzyme 2, cytotoxic T-lymphocyte-associated serine esterase 1) (GZMB) \\
\hline 233.4 & 0.241 & -9.92 & chemokine (C-C motif) ligand 2 (CCL2) \\
\hline 79.35 & 0.087 & -9.83 & hematopoietic cell-specific Lyn substrate 1 (HCLS1) \\
\hline 52.58 & 0.062 & -9.73 & integrin, alpha $X$ (complement component 3 receptor 4 subunit) (ITGAX) \\
\hline 83.38 & 0.112 & -9.53 & ADAM metallopeptidase domain 8 (ADAM8) \\
\hline 83.38 & 0.112 & -9.53 & ADAM metallopeptidase domain 8 (ADAM8) \\
\hline
\end{tabular}


Table 1. contd....

\begin{tabular}{|l|l|l|l|}
\hline 55.27 & 0.078 & -9.46 & caspase 1, apoptosis-related cysteine peptidase (interleukin 1beta convertase) (CASP1) \\
\hline 92.43 & 0.138 & -9.39 & chemokine (C-C motif) ligand 20 (CCL20) \\
\hline 158.6 & 0.249 & -9.31 & secreted phosphoprotein 1 (osteopontin, bone sialoprotein I, early T-lymphocyte activation 1) (SPP1) \\
\hline 138.7 & 0.226 & -9.26 & interleukin 8 (IL8) \\
\hline
\end{tabular}

* genes are aligned by order of decreasing $\log 2$ ratio.

\section{Table 2. Genes of polyIC-Stimulated PBMC Upregulated by F(ab')2 Treatment}

\begin{tabular}{|c|c|c|c|}
\hline Control & $\mathbf{F}\left(\mathbf{a b}^{\prime}\right) 2$ & Log2Ratio & Description \\
\hline 2.3 & 140.6 & 5.95 & insulin-like growth factor binding protein $2,36 \mathrm{kDa}$ (IGFBP2) \\
\hline 2.9 & 67.8 & 4.54 & phosphoribosylaminoimidazole carboxylase (PAICS) \\
\hline 4.1 & 86.1 & 4.38 & procollagen-lysine, 2-oxoglutarate 5-dioxygenase 3 (PLOD3) \\
\hline 3.2 & 65.3 & 4.36 & insulin-like growth factor binding protein 7 (IGFBP7) \\
\hline 3.4 & 58.2 & 4.09 & IMP (inosine monophosphate) dehydrogenase 1 (IMPDH1) \\
\hline 4.5 & 65.9 & 3.87 & destrin (actin depolymerizing factor) (DSTN) \\
\hline 4.6 & 57.1 & 3.62 & sema domain (semaphorin) 4C (SEMA4C) \\
\hline 6.9 & 78.7 & 3.52 & polymerase (RNA) II (DNA directed) polypeptide F (POLR2F) \\
\hline 3.6 & 41.4 & 3.52 & peroxiredoxin 4 (PRDX4) \\
\hline 9.2 & 82.9 & 3.17 & heat shock $105 \mathrm{kDa} / 110 \mathrm{kDa}$ protein 1 (HSPH1) \\
\hline 8 & 68 & 3.09 & peripheral myelin protein 22 (PMP22) \\
\hline 5.2 & 44.5 & 3.09 & cytochrome c oxidase subunit $\mathrm{Va}(\mathrm{COX} 5 \mathrm{~A})$ \\
\hline 5.2 & 42.4 & 3.04 & S-adenosylhomocysteine hydrolase (AHCY) \\
\hline 7.5 & 56.9 & 2.93 & NADH dehydrogenase (ubiquinone) 1, subcomplex unknown, 1,6kDa (NDUFC1) \\
\hline 9.3 & 67.2 & 2.85 & complement component $1, \mathrm{q}$ subcomponent binding protein(C1QBP) \\
\hline 8.2 & 49.8 & 2.61 & phosphatidylethanolamine binding protein 1 (PEBP1) \\
\hline 11.1 & 66.9 & 2.58 & malate dehydrogenase 1, NAD (soluble) (MDH1) \\
\hline 30.3 & 180.2 & 2.56 & heat shock 60kDa protein 1 (chaperonin) (HSPD1) \\
\hline 21.1 & 122.6 & 2.54 & matrix metallopeptidase 1 (interstitial collagenase) (MMP1) \\
\hline 19.4 & 98.6 & 2.35 & heat shock 70kDa protein 4 (HSPA4) \\
\hline 44.4 & 214.6 & 2.26 & macrophage migration inhibitory factor (glycosylation-inhibiting factor) (MIF) \\
\hline 20.2 & 97.2 & 2.26 & heat shock 10kDa protein 1 (chaperonin 10) (HSPE1) \\
\hline 26 & 123.9 & 2.26 & chaperonin containing TCP1, subunit 2 (beta) (CCT2) \\
\hline 11 & 48.8 & 2.14 & DEAD (Asp-Glu-Ala-Asp) box polypeptide 27 (DDX27) \\
\hline 9.3 & 40.2 & 2.1 & chondroitin sulfate synthase 1 (CHSY1) \\
\hline 12.7 & 52.8 & 2.04 & Fas-activated serine/threonine kinase (FASTK) \\
\hline 11.7 & 48.1 & 2.04 & cysteinyl-tRNA synthetase 2 , mitochondrial (putative) (CARS2) \\
\hline 11.6 & 43.9 & 1.93 & proteasome (prosome, macropain) subunit, beta type, 7 (PSMB7) \\
\hline 11.4 & 43.5 & 1.93 & prohibitin 2 (PHB2) \\
\hline 18.7 & 70.9 & 1.93 & low density lipoprotein receptor-related protein-associated protein 1 (LRPAP1) \\
\hline 11.2 & 42.6 & 1.93 & DEAD (Asp-Glu-Ala-Asp) box polypeptide 54 (DDX54) \\
\hline 20.5 & 76.5 & 1.89 & prostaglandin E synthase 3 (cytosolic) (PTGES3) \\
\hline 27.3 & 101.5 & 1.89 & lamin A/C (LMNA) \\
\hline
\end{tabular}


Table 2. contd....

\begin{tabular}{|c|c|c|l|}
\hline 29.8 & 110.7 & 1.89 & heat shock protein 90kDa alpha (cytosolic), class A member 1 (HSP90AA1) \\
\hline 60.3 & 224.5 & 1.89 & glutathione S-transferase pi (GSTP1) \\
\hline 12.1 & 43.4 & 1.85 & chaperonin containing TCP1, subunit 3 (gamma) (CCT3) \\
\hline 32.9 & 114.5 & 1.81 & lactate dehydrogenase B (LDHB) \\
\hline 24.1 & 83.6 & 1.81 & calmodulin 2 (phosphorylase kinase, delta) (CALM2) \\
\hline 14.6 & 50.1 & 1.77 & SP100 nuclear antigen (SP100) \\
\hline 13.6 & 44.8 & 1.72 & heat shock factor binding protein 1 (HSBP1) \\
\hline 15 & 47.8 & 1.68 & methionyl aminopeptidase 2 (METAP2) \\
\hline 43.5 & 136.8 & 1.63 & chaperonin containing TCP1, subunit 4 (delta) (CCT4) \\
\hline 13.5 & 41.1 & 1.58 & prefoldin subunit 2 (PFDN2) \\
\hline
\end{tabular}

* genes are aligned by order of decreasing $\log 2$ ratio.

showed similar inhibitory activity to PAMPs induced cytokine production, thus the action might be mediated mainly through antigen binding sites in this experimental system. To analyze the inhibitory action of immunoglobulin preparation on cytokine synthesis more precisely, we further analyzed $\mathrm{F}\left(\mathrm{ab}^{\prime}\right)_{2}$ mediated inhibition.

\section{Microarray Analysis of Inhibitory Action of $F\left(a b^{\prime}\right)_{2}$ on Cytokine Production}

Modulation of gene expression of PBMC by IVIg was more precisely analyzed by microarray analysis. Gene expression of the PBMC stimulated by Poly I:C at $10 \mu \mathrm{g} / \mathrm{ml}$ for $3 \mathrm{~h}$ in the presence or absence of $\mathrm{F}\left(\mathrm{ab}^{\prime}\right)_{2}$ were compared. Analyzing the gene expression patterns, expression of 229 genes was inhibited to $1 / 200$ or less by $F\left(a^{\prime}\right)_{2}$. Genes of significant reduction are listed in Table $\mathbf{1}$. On the other hand, expression of 159 genes were increased by more than 100fold by $\mathrm{F}\left(\mathrm{ab} \mathrm{b}^{\prime}\right)_{2}$. . Genes of significant augmentation are listed in Table 2. According to this analysis, $F\left(a b^{\prime}\right)_{2}$ clearly inhibited and amplified numerous genes. The genes analyzed had many functions, suggesting that various mechanisms were involved in the inhibition.

\section{DISCUSSION}

The most important function of immune system is believed to be distinguish self from harmful non-self to maintain homeostasis of the host. It is also true that autoimmunity always exist in some degree to control homeostasis. Inballance of the autoimmunity induce autoimmune diseases. More than 80 kind of autoimmune diseases are known and are commonly difficult for medical treatment. Mechanism of autoimmunity and autoimme diseases are actively underway all over the world and it is generally accepted that the mechanism include both the genetic factors and the environmental factors [7, 8]. Microbial infection is one of the environmental mechanisms for the autoimmune diseases [25]. Infectious diseases activate both innate and acquired immunity, and all these mechanisms might be related to autoimmune diseases. From the view point of innate immunity, there are many PAMPs to activate neutrophils, macrophages, T- cells as well as B-cells. Some of the PAMPs activate lymphocytes polyclonally. From acquired immunity, molecular mimicry activates crossreactive $\mathrm{T}$ cells that recognize both the pathogen-derived epitopes and the self-derived epitopes, and then mediate self-tissue damage. Self-reactive $\mathrm{T}$ cells are also activated by non-specific bystander mechanism during infection. In addition, epitope spreading involves a persistent pathogen infection that causes damage to self-tissue.

Clinical findings have demonstrated that IVIg improves symptoms associated with hypercytokinemia in patients with serious autoimmune diseases, such as Kawasaki disease, and Guillain-Barré syndrome [18, 19], and that the mechanism involves the direct or indirect action of IVIg on macrophages, NK cells, granulocytes, B cells or T cells [8, 9, 20]. In this study, the effects of S-IVIg and $\mathrm{F}(\mathrm{ab})_{2}$ on PAMPinduced cytokine production of PBMCs were examined. The action of IVIg on TNF- $\alpha$ production induced by PAMPs was examined and found that the production was significantly inhibited by both S-IVIg and $\mathrm{F}\left(\mathrm{ab}^{\prime}\right)_{2}$. There are several reports of the effects of IVIg on cytokine production by human PBMCs. With respect to cytokine production induced by a mixed lymphocyte reaction (MLR), the productions of interleukin (IL)-2, interferon (IFN)- $\gamma$, TNF- $\alpha$, and IL-6 were inhibited by IVIg [21], and the inhibitory action of IVIg on IL2 production was stronger than that of $F\left(a b^{\prime}\right)_{2}$ [22]. With respect to cytokine production induced by LPS, the production of IL-6, TNF- $\alpha$, and IL- 8 was inhibited [18, 23, 24], supporting the results shown in this study.

Immuneglobulin is composed of two functional domains, Fab fragment and Fc fragment. Fc fragment is important for the opsonization of the immune complex and following inflammatory responses. In the preliminary investigation, we compared the cytokine synthesis of PBMCs stimulated with aqueous and plate bound IVIg, and found that the plate bound IVIg induced significant amount of cytokines (Fig. 1), but the former did not (data not shown). From these findings, cross-linking of $\mathrm{Fc}$ receptor is significantly important for stimulating PBMCs by IVIg directly. Data shown in Fig. (2) indicated that both whole immunogulobulin molecule and $\mathrm{F}(\mathrm{ab})_{2}$ fragment inhibited cytokine synthesis almost equally. In addition, we also found that $\mathrm{F}\left(\mathrm{ab}{ }^{\prime}\right)_{2}$ fragment did not induce cytokines even by binding to the culture plate (Fig. 4). In the present study, the purpose is to analyze the PAMPs mediated activation of PBMCs and its inhibition by immunoglobulin preparation, thus, we used aqueous $\left.\mathrm{F}(\mathrm{ab})_{2}\right)_{2}$ fragment for the precise examination. 
The inhibitory action of $\mathrm{F}\left(\mathrm{ab}^{\prime}\right)_{2}$ on Poly I:C-induced PBMCs response was comprehensively analyzed at the gene expression level using a microarray. Characteristic gene experssion changes are shown in the Tables 1 and 2. TNF- $\alpha$ production was inhibited by approximately $5.4 \times 10^{-4}$ times, even at the gene expression level. In addition, the expression of other inflammatory cytokines, including IL-1 $\beta$, IL-6, IL-8, Oncostatin M (OSM), and IFN- $\gamma$, were also inhibited. Chemokines involved in cell mobilization, as well as chemokine receptors, were also inhibited. Cytokine receptors and adhesion molecules were also inhibited. In addition, a wide range of molecules involved in inflammation, including TLR2, urokinase type plasminogen activator receptor (UPAR), lysozyme (LZM), ficolin, and caspase, were also inhibited. According to these results, it was suggested that (1) IVIg inhibits inflammatory PAMP-induced cytokine production by PBMCs, (2) the inhibitory action is broad and inhibit various types of PAMPs or receptors, and (3) there is a possibility of inhibition at the gene expression level.

In contrast, the expressions of numerous genes were found to be enhanced by IVIg. As the expression levels in the control group varied considerably, only genes with relatively high expression levels and genes that demonstrated considerable relative changes were selected and included in the table. A large number of genes involved in cell survival were observed, including channel, proteasome, heat shock protein (HSP), chaperonin, oxidoreductase, and detoxification enzyme genes. Moreover, increases in the expression of inflammation-related molecules were observed. For example, chondroitin sulfate synthetase is involved in the promotion of matrix synthesis while, at the same time, matrix metalloproteinase 1 (MMP1) and tissue inhibitor of metalloproteinase 2 (TIMP2) control tissue metabolism by promoting and inhibiting decomposition. Super Oxide Dismutase 1 (SOD1) is essential for the elimination of oxidative stress.

Microarray analysis reconfirmed that the action of IVIg is extremely diverse, as exemplified by enhancement and inhibition of the expression of an extremely large number of genes. As shown in Fig. (1), IVIg suppressed TNF- $\alpha$ synthesis of PBMC stimulated with several PAMPs. Signaling mechanism of these PAMPs share many part in the downstream signals of TLRs, such as MyD88 and TIR [11-15, 26]. From these findings, genes inhibited and augmented by other PAMPs may include major similarity.

In the present study, anti-inflammatory mechanisms of IVIg were analyzed from the view point of PAMPs induced cytokine syntheses and gene expression. The most striking data interested in this study was the similar inhibitory effect of IVIg and F(ab')2 fragment. A part of the antiinflammatory action of IVIg would be mediated through the Fc-fragment of the immunoglobulin molecule. In the PAMPs stimulated cytokine production, $\mathrm{F}(\mathrm{ab}$ ')2 fragment acted almost equally with the whole immunoglobulin molecule, at least in this experimental system. In general, Fc-fragment is a key moiety for inducing inflammatory response, $F(a b ') 2$ might be beneficial for the clinical use. From the view point of microbial infection and autoimmune disease, variety of mechanisms should be concerned in addition to the PAMPs mediated inflammatory responses [27, 28]. Further analysis is needed for the precisely examine the whole mechanism of autoimmune disease and the effect of IVIg.

\section{ACKNOWLEDGEMENTS}

We thank Yuiko Miura for excellent technical assistance. This study was supported in part by a grant from the Japanese Ministry of Health, Labor, and Welfare.

\section{CONFLICT OF INTEREST STATEMENT}

The author confirms that this article content has no conflicts of interest.

\section{REFERENCES}

[1] Imbach P, Barandun S, D'Apuzzo V, et al. High-dose intravenous gammaglobulin for idiopathic thrombocytopenic purpura in childhood. Lancet 1981; 1: 1228-31.

[2] Van der Laan-Baalbergen NE, Mollema SA, Kritikos H, et al. Heart failure as presenting manifestation of cardiac involvement in systemic lupus erythematosus. Neth J Med 2009; 67: 295-301.

[3] Zandman-Goddard G, Blank M, Shoenfeld Y. Intravenous immunoglobulins in systemic lupus erythematosus: from the bench to the bedside. Lupus 2009; 18: 884-8.

[4] Fillit H, Hess G, Hill J, Bonnet P, Toso C. IV immunoglobulin is associated with a reduced risk of Alzheimer disease and related disorders. Neurology 2009; 73: 180-5.

[5] Carp HJ, Asherson RA, Shoenfeld Y. Intravenous immunoglobulin in pregnancies complicated by the antiphospholipid syndrome: what is its role? J Clin Rheumatol 2001; 7: 291-4.

[6] Saquib R, Melton LB, Chandrakantan A, et al. Disseminated adenovirus infection in renal transplant recipients: the role of cidofovir and intravenous immunoglobulin. Transpl Infect Dis 2010; 12: 7783.

[7] Nimmerjahn F, Ravetch JV. Anti-inflammatory actions of intravenous immunoglobulin. Annu Rev Immunol 2008; 26: 513-33.

[8] Imbach P, Lazarus AH, Kühne T. Intravenous immunoglobulins induce potentially synergistic immunomodulations in autoimmune disorders. Vox Sang 2010; 98: 385-94.

[9] Tha-In T, Bayry J, Metselaar HJ, Kaveri SV, Kwekkeboom J. Modulation of the cellular immune system by intravenous immunoglobulin. Trends Immunol 2008; 29: 608-15.

[10] Clynes R. IVIG therapy: interfering with interferon-gamma. Immunity 2007; 26: 4-6.

[11] Re F, Strominger JL. Separate functional domains of human md-2 mediate toll-like receptor 4-binding and lipopolysaccharide responsiveness. J Immunol 2003;171:5272-86.

[12] Yamamoto M, Sato S, Hemmi H, et al. Role of adaptor TRIF in the MyD88-independent toll-like receptor signaling pathway. Science 2003; 301: 640-3.

[13] Ozinsky A, Underhill DM, Fontenot JD, et al. The repertoire for pattern recognition of pathogens by the innate immune system is defined by cooperation between toll-like receptors. Proc Natl Acad Sci U S A 2000; 97: 13766-71.

[14] Chu WM, Ostertag D, Li ZW, Chang L, et al. JNK2 and IKKbeta are required for activating the innate response to viral infection. Immunity 1999; 11: 721-31.

[15] Alexopoulou L, Holt AC, Medzhitov R, Flavell RA. Recognition of double-stranded RNA and activation of NF-kappaB by Toll-like receptor 3. Nature 2001; 413: 732-8.

[16] Nagi-Miura N, Shingo Y, Kurihara K, Adachi Y, Suzuki K, Ohno $\mathrm{N}$. Involvement of platelet activating factor, histamine and serotonin in acute lethal shock induced by Candida albicans watersoluble extracellular polysaccharide fraction (CAWS) in mice. Biol Pharm Bull 2007; 30: 1354-7.

[17] Hida S, Miura NN, Adachi Y, Ohno N. Effect of Candida albicans cell wall glucan as adjuvant for induction of autoimmune arthritis in mice. J Autoimmun 2005; 25: 93-101.

[18] Gupta M, Noel GJ, Schaefer M, Friedman D, Bussel J, JohannLiang R. Cytokine modulation with immune gamma-globulin in peripheral blood of normal children and its implications in Kawasaki disease treatment. J Clin Immunol 2001; 21: 193-9. 
[19] Sharief MK, Ingram DA, Swash M, Thompson EJ. I.v. immunoglobulin reduces circulating proinflammatory cytokines in GuillainBarré syndrome. Neurology 1999; 52: 1833-8.

[20] Teeling JL, Bleeker WK, Rigter GM, van Rooijen N, Kuijpers TW, Hack CE. Intravenous immunoglobulin preparations induce mild activation of neutrophils in vivo via triggering of macrophages-studies in a rat model. Br J Haematol 2001; 112: 1031-40.

[21] Nachbaur D, Herold M, Gächter A, Niederwieser D. Modulation of alloimmune response in vitro by an IgM-enriched immunoglobulin preparation (Pentaglobin). Immunology 1998; 94: 279-83.

[22] Nachbaur D, Herold M, Eibl B, et al. A comparative study of the in vitro immunomodulatory activity of human intact immunoglobulin (7S IVIG), F(ab')2 fragments (5S IVIG) and Fc fragments. Evidence for post-transcriptional IL-2 modulation. Immunology 1997; 90: $212-8$.
[23] Hamada H, Terai M. Treatment for Kawasaki diseaseperspective. Nihon Rinsho 2008; 66: 360-4.

[24] Andersson U, Björk L, Skansén-Saphir U, Andersson J. Pooled human $\operatorname{IgG}$ modulates cytokine production in lymphocytes and monocytes. Immunol Rev 1994; 139: 21-42.

[25] Delogu LG, Deidda S, Delitala G, Manetti R. Infectious diseases and autoimmunity. J Infect Dev Ctries 2011; 5: 679-87

[26] Mills KH. TLR-dependent T cell activation in autoimmunity. Nat Rev Immunol 2011; 11: 807-22.

[27] Stübgen JP. Immune-mediated myelitis associated with hepatitis virus infections. J Neuroimmunol 2011; 239: 21-7.

[28] Hasni S, Ippolito A, Illei GG. Helicobacter pylori and autoimmune diseases. Oral Dis 2011; 17: 621-7.

Received: June 20, 2012

Revised: July 15,2012

Accepted: July 17, 2012

(C) Yamamoto et al.; Licensee Bentham Open.

This is an open access article licensed under the terms of the Creative Commons Attribution Non-Commercial License (http://creativecommons.org/licenses/by-nc/3.0/) which permits unrestricted, non-commercial use, distribution and reproduction in any medium, provided the work is properly cited. 